\title{
The relationship between anemia at admission and outcome in patients older than 60 years with hip fracture
}

\author{
Tetsuo Hagino - Satoshi Ochiai · Eiichi Sato • \\ Shingo Maekawa · Masanori Wako · Hirotaka Haro
}

Received: 5 December 2008/Accepted: 12 July 2009/Published online: 26 August 2009

(C) Springer-Verlag 2009

\begin{abstract}
Background We have reported that the functional outcome in elderly with hip fracture is related to age at admission, dementia, and anemia. In this study, we examined the relationship between hemoglobin level at admission and walking ability, as well as survival outcome at discharge.

Materials and methods We studied 394 patients aged 60 years or older treated at our hospital for hip fracture since 1997. Anemia was defined as an admission hemoglobin level $<13.0 \mathrm{~g} / \mathrm{dl}$ for men and $<12.0 \mathrm{~g} / \mathrm{dl}$ for women. The relationships between anemia status with age at admission, gender, fracture type, residence before injury, walking ability at discharge, length of hospital stay, and survival outcome were analyzed.

Results Anemia was observed in 266 of 394 patients. Univariate analysis identified no relationship between the status of anemia and age, gender, walking ability before injury, treatment modality, or length of hospital stay. On the other hand, 106 of 266 patients in the anemic group were residing in institutions, and as many as $72.9 \%$ of patients in the anemic group had trochanteric fracture. For walking ability at discharge, 92 of 128 patients without anemia were ambulatory compared with only 130 of 266 patients with anemia, with a significant difference between
\end{abstract}

T. Hagino $(\varangle) \cdot$ S. Ochiai $\cdot$ M. Wako

Department of Orthopaedic Surgery, National Hospital

Organization, Kofu National Hospital,

11-35 Tenjin-cho, Kofu, Yamanashi 400-8533, Japan

e-mail: tmhagino@amber.plala.or.jp

E. Sato $\cdot$ S. Maekawa $\cdot$ H. Haro

Department of Orthopaedic Surgery, Interdisciplinary Graduate

School of Medicine and Engineering, University of Yamanashi,

Chuo, Yamanashi, Japan the two groups. Furthermore, there were 15 in-hospital deaths in the anemic group compared with one death in the nonanemic group. Multivariate analysis identified three independent items: age, fracture type, and walking ability at discharge, as related to the status of anemia.

Conclusions Hemoglobin level at admission is related to outcome in patients with hip fracture.

Keywords Anemia - Hip fractures - Hemoglobin . Elderly

\section{Introduction}

In patients who sustain a hip fracture, general status at admission affects the outcome. We have reported that the functional outcome of elderly patients with hip fracture is affected by age and status of dementia and anemia [1, 2]. In addition, Muramoto et al. [3] reported that hemoglobin level at admission is related to functional and survival outcome of hip fracture patients aged 90 or older. However, there are few detailed studies on the relationship between anemia at admission and outcome of patients with hip fracture $[4,5]$. In this study, we examined the relationship of hemoglobin level at admission with walking ability and survival outcome at discharge.

\section{Materials and methods}

Between 1 January 1997 and 31 May 2006, 394 patients ( 89 men, 305 women) aged 60 or older were treated at the National Kofu Hospital for hip fracture. This hospital is a self-contained regional hospital with an orthopedic department and an in-hospital rehabilitation facility, which 
provides care for patients with acute injury. However, we do not have affiliated rehabilitation or long-term-care facilities. The study was approved by the Ethical Committee of the National Kofu Hospital. Enrolled patients gave informed consent.

This patient group was studied retrospectively. All patients were examined at the time of admission and were followed. Information regarding preinjury living status was obtained by interview with the patient or family member. Data on health status and discharge status were collected by reviewing clinical charts during hospitalization and at discharge. The age at injury ranged from 60 to 103 years, with a mean of 82.8 years. The fracture type was femoral neck fracture in 125 cases and trochanteric fracture in 269 cases. Surgery was conducted in 347 patients, 163 of whom received open reduction using compression hip screw, 63 had femoral head replacement, in 46 patients a Hansson pin was used, in 32 a gamma nail, in 22 a twin-hook system [6], and in 21 other devices were used. The remaining 47 patients received conservative treatment for various reasons, including refusal of surgery by the family. The 394 patients were classified as anemic when the hemoglobin level at admission was $<13.0 \mathrm{~g} / \mathrm{dl}$ for men and $<12.0 \mathrm{~g} / \mathrm{dl}$ for women. Anemic patients were further subclassified as severe anemia when hemoglobin level was $10 \mathrm{~g} / \mathrm{dl}$ or below and as mild anemia when at higher levels [5].

Next, the subjects were investigated for nine parameters, including gender, age younger than 85 years and 85 years or older, residence before injury, fracture type, treatment modality, and walking ability before injury and at discharge. Univariate analysis was conducted to examine the relationship between the status of anemia and each of the above parameters. Then, multivariate analysis was conducted by logistic regression analysis, using the parameters that showed a significant difference in univariate analysis as independent variables and anemia status as dependent variable. The same analysis was conducted on the subgroup of anemic patients stratified into severe or mild anemia. The goal of hospital discharge was set as recovery of walking ability to the preinjury level. However, for patients who showed no further improvement in walking ability, the goal of discharge was considered to be walking ability at that point. Walking ability at discharge was classified into a group capable of walking independently or with a walking aid (ambulatory group) and a group not capable of walking (nonambulatory group).

\section{Results}

At admission, anemia was observed in 266 (66 men and 200 women) of 394 patients (67.5\%), 94 of whom were severely anemic. Regarding walking ability at discharge,
222 patients $(56.3 \%)$ were ambulatory and 172 patients $(43.7 \%)$ were nonambulatory, the latter included 16 patients who died in hospital. Ninety-nine of 394 patients received blood transfusion during hospitalization.

Comparing the anemic and nonanemic groups, significant differences were observed for age, residence before injury, and fracture type. The anemic group had a high proportion (53\%) of elderly aged 85 or older, and many $(72.9 \%)$ had trochanteric fractures (Table 1). There was no difference in length of hospital stay between the two groups. On the other hand, only 130 of 266 (48.9\%) anemic patients were ambulatory compared with $71.9 \%$ of nonanemic patients, showing a relationship between the status of anemia and walking ability at discharge. Moreover, the in-hospital mortality was also higher in the anemic group (Table 2). Then, multivariate analysis was conducted using the five parameters that showed significant differences in the above analysis (age, residence before injury, fracture type, walking ability at discharge, and in-hospital mortality) as independent variables. Three variables-age, fracture type, and walking

Table 1 General patient characteristics $(n=394)$

\begin{tabular}{|c|c|c|c|}
\hline & $\begin{array}{l}\text { Anemic group } \\
\text { (patients with } \\
\text { anemia at } \\
\text { admission) }\end{array}$ & $\begin{array}{l}\text { Nonanemic } \\
\text { group }\end{array}$ & $P$ value* \\
\hline No. of patients & $266(67.5 \%)$ & $128(32.5 \%)$ & \\
\hline \multicolumn{4}{|l|}{ Gender } \\
\hline Male & $66(24.8 \%)$ & $23(18.0 \%)$ & 0.1282 \\
\hline Female & $200(75.2 \%)$ & $105(82.0 \%)$ & \\
\hline \multicolumn{4}{|l|}{ Age (years) } \\
\hline $60-84$ & $125(47.0 \%)$ & $89(69.5 \%)$ & 0.000026 \\
\hline$\geq 85$ & $141(53.0 \%)$ & $39(30.5 \%)$ & \\
\hline \multicolumn{4}{|l|}{ Preinjury residence } \\
\hline $\begin{array}{l}\text { Nursing home or } \\
\text { hospital }\end{array}$ & $106(39.8 \%)$ & $37(28.9 \%)$ & 0.0344 \\
\hline Own home & $160(60.2 \%)$ & $91(71.1 \%)$ & \\
\hline \multicolumn{4}{|l|}{ Type of fracture } \\
\hline Femoral neck & $72(27.1 \%)$ & $53(41.4 \%)$ & 0.00418 \\
\hline Trochanteric & $194(72.9 \%)$ & $75(58.6 \%)$ & \\
\hline \multicolumn{4}{|l|}{ Treatment modality } \\
\hline Operative & $235(88.3 \%)$ & $112(87.5 \%)$ & 0.8083 \\
\hline Nonopenative & $31(11.7 \%)$ & $16(12.5 \%)$ & \\
\hline \multicolumn{4}{|l|}{$\begin{array}{l}\text { Preinjury walking } \\
\text { ability }^{\mathrm{a}}\end{array}$} \\
\hline Ambulatory & $216(81.2 \%)$ & $112(87.5 \%)$ & 0.1170 \\
\hline Nonambulatory & $50(18.8 \%)$ & $16(12.5 \%)$ & \\
\hline
\end{tabular}


Table 2 Anemia and clinical outcome

\begin{tabular}{|c|c|c|c|c|}
\hline & $\begin{array}{l}\text { Anemic group } \\
(n=266)\end{array}$ & $\begin{array}{l}\text { Nonanemic } \\
\text { group } \\
(n=128)\end{array}$ & \multicolumn{2}{|c|}{$P$ value } \\
\hline $\begin{array}{l}\text { Length of } \\
\text { hospital stay }\end{array}$ & $69.5 \pm 44.7$ days & \multirow[t]{2}{*}{$64.9 \pm 33.9$ days } & \multicolumn{2}{|c|}{$0.3099 *$} \\
\hline \multicolumn{4}{|c|}{ Ambulation status at discharge } & \\
\hline Ambulatory & $130(48.9 \%)$ & $92(71.9 \%)$ & \multirow{2}{*}{\multicolumn{2}{|c|}{$0.000016^{* *}$}} \\
\hline Nonambulatory & $136(51.1 \%)$ & $36(28.1 \%)$ & & \\
\hline \multicolumn{5}{|c|}{ In-hospital mortality } \\
\hline In-hospital death & $15(5.6 \%)$ & $1(0.8 \%)$ & \multirow{2}{*}{\multicolumn{2}{|c|}{$0.0262 * * *$}} \\
\hline $\begin{array}{l}\text { Alive at } \\
\text { discharge }\end{array}$ & $251(94.4 \%)$ & $127(99.2 \%)$ & & \\
\hline \multicolumn{5}{|c|}{$\begin{array}{l}* \text { Student's } t \text { test } \\
* * \text { Chi-square for independence test } \\
* * * \text { Fisher's exact probability test }\end{array}$} \\
\hline \multicolumn{5}{|c|}{$\begin{array}{l}\text { Table } 3 \text { Significant factors for anemia at admission identified by } \\
\text { multivariate analysis }\left(R^{2}=0.135\right)\end{array}$} \\
\hline & & $\begin{array}{l}\text { Odds ratio }(95 \\
\text { confidence } \\
\text { interval) }\end{array}$ & & $P$ value \\
\hline \multicolumn{2}{|l|}{ Age $(\geq 85$ years $)$} & $2.24(1.38-3.6$ & & 0.0011 \\
\hline \multicolumn{2}{|c|}{$\begin{array}{l}\text { Preinjury residence (nursing home or } \\
\text { hospital) }\end{array}$} & $0.98(0.56-1.7$ & & NS \\
\hline \multicolumn{2}{|c|}{ Type of fracture (trochanteric) } & $3.77(2.37-6.0$ & & $<0.0001$ \\
\hline \multicolumn{2}{|c|}{$\begin{array}{l}\text { Ambulation status at discharge } \\
\text { (nonambulatory) }\end{array}$} & $2.12(1.23-3.6$ & & 0.0067 \\
\hline \multicolumn{2}{|c|}{ In-hospital mortality (in-hospital death) } & th) $0.30(0.04-2.4$ & & NS \\
\hline
\end{tabular}

NS Not significant

ability at discharge - were found to be independently related to the status of anemia (Table 3).

Next, 94 patients with severe anemia were compared with 172 patients with mild anemia. By univariate analysis, significant differences were detected for age, fracture type, and survival outcome at discharge, whereas no significant relationship was observed for the other variables (Table 4). The result of multivariate analysis showed a significant relationship between severity of anemia and two variables (Table 5).

\section{Discussion}

Gruson et al. [5] examined 395 hip fracture patients aged $\geq 65$ years and observed anemia at admission in 180 patients $(45.6 \%)$. They reported that anemia at admission was significantly related to length of hospital stay and mortality rate at 6 and 12 months. Halm et al. [4] also
Table 4 Comparison of severely anemic patients with mildly anemic patients

\begin{tabular}{|c|c|c|c|}
\hline & $\begin{array}{l}\text { Severe } \\
\text { anemia }^{\text {a }}\end{array}$ & $\begin{array}{l}\text { Mild } \\
\text { anemia }^{a}\end{array}$ & $\begin{array}{l}P \\
\text { value* }\end{array}$ \\
\hline No. of patients & 94 & 172 & \\
\hline \multicolumn{4}{|l|}{ Gender } \\
\hline Male & $20(213 \%)$ & $46(26.7 \%)$ & \multirow[t]{2}{*}{0.3237} \\
\hline Female & $74(78.7 \%)$ & $126(73.6 \%)$ & \\
\hline \multicolumn{4}{|l|}{ Age (years) } \\
\hline $60-84$ & $34(36.2 \%)$ & $91(52.9 \%)$ & \multirow[t]{2}{*}{0.0089} \\
\hline$\geq 85$ & $60(63.8 \%)$ & $81(47.1 \%)$ & \\
\hline \multicolumn{4}{|l|}{ Preinjury residence } \\
\hline Nursing home or hospital & $37(39.4 \%)$ & $69(40.1 \%)$ & \multirow[t]{2}{*}{0.9044} \\
\hline Own home & $57(60.6 \%)$ & $103(59.9 \%)$ & \\
\hline \multicolumn{4}{|l|}{ Type of fracture } \\
\hline Femoral neck & $13(13.8 \%)$ & $59(34.3 \%)$ & \multirow[t]{2}{*}{0.0003} \\
\hline Trochanteric & $81(86.2 \%)$ & $113(65.7 \%)$ & \\
\hline \multicolumn{4}{|l|}{ Treatment modality } \\
\hline Operative & $83(88.3 \%)$ & $152(88.4 \%)$ & \multirow[t]{2}{*}{0.9856} \\
\hline Nonoperative & $11(11.7 \%)$ & $20(11.6 \%)$ & \\
\hline \multicolumn{4}{|l|}{ Preinjury walking ability } \\
\hline Ambulatory & $72(76.6 \%)$ & $144(83.7 \%)$ & \multirow[t]{2}{*}{0.1551} \\
\hline Nonambulatory & $22(23.4 \%)$ & $28(16.3 \%)$ & \\
\hline Length of hospital stay & $76.7 \pm 53.2$ & $65.5 \pm 38.8$ & 0.564 \\
\hline \multicolumn{4}{|c|}{ Ambulation status at discharge } \\
\hline Ambulatory & $42(44.7 \%)$ & $88(51.2 \%)$ & \multirow[t]{2}{*}{0.3120} \\
\hline Nonambulatory & $52(55.3 \%)$ & $84(48.8 \%)$ & \\
\hline \multicolumn{4}{|l|}{ In-hospital mortality } \\
\hline In-hospital death & $9(9.6 \%)$ & $6(3.5 \%)$ & \multirow[t]{2}{*}{0.0397} \\
\hline Alive at discharge & $85(90.4 \%)$ & $166(96.5 \%)$ & \\
\hline
\end{tabular}

${ }^{a}$ Severe anemia was defined as an admission hemoglobin level $<10.0 \mathrm{~g} / \mathrm{dl}$ for men and women. Mild anemia was defined as an admission hemaglobin level between 10.0 and $11.9 \mathrm{~g} / \mathrm{dl}$ for women and between 10.0 and $12.9 \mathrm{~g} / \mathrm{dl}$ for men

* Chi-square for independence test, Student's $t$-test. Fisher's exact probability test as appropriate

Table 5 Significant factors for severe anemia at admission identified by multivariate analysis $\left(R^{2}=0.064\right)$

\begin{tabular}{lll}
\hline & $\begin{array}{l}\text { Odds ratio } \\
\text { (95\% confidence } \\
\text { interval) }\end{array}$ & $P$ value \\
\hline Age ( $\geq 85$ years) & $1.80(0.05-3.08)$ & 0.0316 \\
Type of fracture (trochanteric) & $3.16(1.61-6.20)$ & 0.0008 \\
In-hospital mortality (in-hospital death) & $0.42(0.14-1.28)$ & NS
\end{tabular}

NS Not significant

observed anemia (hemoglobin $<12.0 \mathrm{~g} / \mathrm{dl}$ ) at admission in $40.4 \%$ of 550 patients with hip fracture, and reported that anemia at admission is related to the length of hospital stay and death or readmission within 60 days. Furthermore, a 
delay in surgery has been found to worsen the outcome. Blom et al. [7] investigated the factors that contributed to surgical delay and identified predictors, including preoperative anemia, in addition to American Society of Anesthesiologists (ASA) classification, urinary tract infection, and chest infection, leading to a conclusion that the presence of a preoperative medical condition has an important effect on surgical delay for a hip fracture. Our study also showed a correlation between hemoglobin at admission and functional and survival outcome of hip fracture, confirming a relationship between anemia at admission and outcome.

Postoperative anemia and transfusion in hip fracture patients have also been studied. Lawrence et al. [8] investigated the relationship between postoperative hemoglobin level and outcome and concluded that higher postoperative hemoglobin level may improve functional recovery after hip fracture repair. On the other hand, Carson et al. [9] analyzed the relationship between postoperative blood transfusion and mortality in hip fracture surgical patients aged 60 or older and found no definite relationship between the two. These findings suggest that postoperative anemia is affected by factors such as the waiting period until surgery and surgical modality but does not reflect the general status of the patient before injury.

We propose that hemoglobin level at admission is an indicator of the general status of the patient before injury and is a predicator of outcome. In our study, anemia at admission correlates with fracture type, and many anemic patients had trochanteric fracture. Almost all patients with trochanteric fracture visited the hospital immediately after injury and underwent blood tests while still in a state of dehydration. Halm et al. [4] suggested that many elderly patients may be dehydrated on admission, and the initial fluid hydration may decrease hemoglobin levels. Therefore, low hemoglobin level at admission is not due to bleeding from trochanteric fracture but reflects anemia before injury. Our finding also suggests that anemic patients are more susceptible to trochanteric fracture. From our finding of a correlation between age and anemia, together with reports of an increase in incidence of trochanteric fracture with advancing age [10] and a higher risk of fall in anemic elderly patients [11, 12], elderly patients with anemia may be more prone to sustain trochanteric fracture as a result of a fall.

Halm et al. [4] explains that the degree of anemia is probably a strong, independent, prognostic factor because it is a marker of underlying comorbid illness burden and physiologic reverse. Therefore, patients found to have anemia at admission are likely to have a poor general status, even before injury. The above findings indicate that for patients with anemia at admission, careful systemic management together with early surgery and rehabilitation contribute to achieving favorable outcome.

Conflict of interest statement No benefits in any form have been received or will be received from a commercial party related directly or indirectly to the subject of this article.

\section{References}

1. Hagino T, Sato E, Tonotsuka H, Ochiai S, Tokai M, Hamada Y (2006) Prediction of ambulation prognosis in the elderly after hip fracture. Int Orthop 30:315-319

2. Hagino T, Ochiai S, Wako M, Sato E, Maekawa S, Senga S, Sugiyama H, Hamada Y (2007) A simple scoring system to predict ambulation prognosis after hip fracture in the elderly. Arch Orthop Trauma Surg 127:603-606

3. Muramoto A, Warashina $\mathrm{H}$, Matsumoto $\mathrm{T}$, Inoue $\mathrm{H}$, Horii $\mathrm{E}$, Osawa Y (2007) Predictors of mortality and functional recovery after hip fracture in elderly patients over 90 years old. J Jpn Orthop Assoc 81:S56

4. Halm EA, Wang JJ, Boockvar K, Penrod J, Silberzweig SB, Magaziner J, Koval KJ, Siu AL (2004) The effect of perioperative anemia on clinical and functional outcomes in patients with hip fracture. J Orthop Trauma 18:369-374

5. Gruson KI, Aharonoff GB, Egol KA, Zuckerman JD, Koval KJ (2002) The relationship between admission hemoglobin level and outcome after hip fracture. J Orthop Trauma 16:39-44

6. Hagino T, Ochiai S, Wako M, Sato E, Maekawa S, Hamada Y (2008) Twin hook fixation for proximal femoral fractures. J Orthop Surg (Hong Kong) 16:162-164

7. Blom BJ, van Dis H, Simons MP, Willems WJ (2007) The relationship between surgical delay for a hip fracture and the complication risk. Ned Tijdschr Geneeskd 151:2050-2054

8. Lawrence VA, Silverstein JH, Cornell JE, Pederson T, Noveck H, Carson JL (2003) Higher Hb level is associated with better early functional recovery after hip fracture repair. Transfusion 43:1717-1722

9. Carson JL, Duff A, Berlin JA, Lawrence VA, Poses RM, Huber EC, O'Hara DA, Noveck H, Strom BL (1998) Perioperative blood transfusion and postoperative mortality. JAMA 279:199205

10. Committee for Osteoporosis Treatment of The Japanese Orthopaedic Association (2004) Nationwide survey of hip fractures in Japan. J Orthop Sci 9:1-5

11. Dharmarajan TS, Avula S, Norkus EP (2007) Anemia increases risk for falls in hospitalized older adults: an evaluation of falls in 362 hospitalized, ambulatory, long-term care, and community patients. J Am Med Dir Assoc 8:e9-e15

12. Dharmarajan TS, Norkus EP (2004) Mild anemia and the risk of falls in older adults from nursing homes and the community. $J$ Am Med Dir Assoc 5:395-400 